Case Report

\title{
An Autopsy Case of Fulminant Amebic Colitis in a Patient with a History of Rheumatoid Arthritis
}

\author{
Naoko Kawabe, Fuyuki Sato, Miho Nagasawa, Masako Nakanishi, and Yasuteru Muragaki \\ Department of Pathology, Wakayama Medical University School of Medicine, Wakayama 641-8509, Japan \\ Correspondence should be addressed to Fuyuki Sato; satof@wakayama-med.ac.jp
}

Received 7 April 2016; Accepted 11 May 2016

Academic Editor: Shadi Hamoud

Copyright (C) 2016 Naoko Kawabe et al. This is an open access article distributed under the Creative Commons Attribution License, which permits unrestricted use, distribution, and reproduction in any medium, provided the original work is properly cited.

\begin{abstract}
Generally, amebic colitis is localized around the mucosal membrane and often accompanied by diarrhea and abdominal pain. We describe a patient with a history of rheumatoid arthritis who had received prolonged steroid therapy. The patient complained of breathing difficulties because of rheumatoid lung disease. Although the patient was given antibacterial agent, the symptoms did not improve until death. We did an autopsy and found that he had fulminant amebic colitis, although the patient was not previously examined. Histochemical analysis revealed severe inflammation and full-thickness necrosis of the colon by ameba, suggesting the involvement of ameba in the progression of the overall condition.
\end{abstract}

\section{Introduction}

Rheumatoid arthritis (RA) patients have high risk of infections by cytomegalovirus, pneumocystis jirovecii, and nontuberculous mycobacterium [1]. Hashimoto and Matsui reported infectious lesions: $52 \%$ of respiratory system, $11 \%$ of kidney and urinary organs, 10\% of gastrointestinal system, and $8 \%$ of skin and soft tissues [1]. It has been reported that treating autoimmune hepatitis patient with prolonged steroid induced amebic encephalitis [2]. In addition, prolonged steroid treatment and further steroid administration of $10 \mathrm{mg} /$ day induced the progression of amebic colitis and pulmonary infections [3-6].

\section{Case Presentation}

A 74-year-old man with a history of RA has received prolonged steroid therapy. He was treated with steroid for at least 1 week during the hospitalization, but we could not obtain how long he had been treated with steroid therapy before the hospitalization of university. Several months before his death, the patient was suspected to have respiratory distress and deterioration of rheumatic symptoms and was diagnosed with interstitial pneumonia by chest CT. Rheumatic symptoms were improved by steroid therapy, but fever and inflammatory reaction continued. Therefore, he was treated with internal antibacterial agent. Since his symptoms continued even after those treatments, he was hospitalized.

Laboratory examinations on admission showed white blood cells at $21.8 \times 10^{9} / \mathrm{L}, \mathrm{C}$-reactive protein $(\mathrm{CRP})$ at $23.51 \mathrm{mg} / \mathrm{dL}$, albumin (Alb) at $1.8 \mathrm{~g} / \mathrm{dL}$, Krebs von den Lungen-6 (KL-6) at $486 \mathrm{U} / \mathrm{mL}$, surfactant protein A (SP-A) at $27.4 \mathrm{ng} / \mathrm{mL}$, surfactant protein $\mathrm{D}(\mathrm{SP}-\mathrm{D})$ at $40.7 \mathrm{ng} / \mathrm{mL}$, procalcitonin (PCT) at $0.17 \mathrm{ng} / \mathrm{mL}$, and creatinine (Cre) at $0.68 \mathrm{mg} / \mathrm{dL}$. On the same day, chest CT showed ground-glass opacity and reticular shadow in the left middle and inferior lobes as well as the left inferior lingular segment. Because his procalcitonin elevated, he was treated with piperacillin and tazobactam for infectious diseases. For the hypoalbuminemia, he was treated with a supplementation of albumin. However, his fever did not improve, suggesting progression of rheumatic lung disease. Therefore, he was given prednisolone at $60 \mathrm{mg} /$ day. On hospital day six, he had onset of diarrhea and bloody stool, which might be caused by the side effect of the antibacterial drug. On day eight, because his procalcitonin level was even higher than on admission day, steroid was stopped. On day ten, he had recurrent fever and increased white blood cells and CRP and was given $1 \mathrm{~g}$ of prednisolone for three hours. On day 13, his Cre increased, while urine volume decreased. He was prescribed predonisolone $60 \mathrm{mg} /$ day. On day 15, his CRP was at $29.15 \mathrm{mg} / \mathrm{dL}$. On that day, 


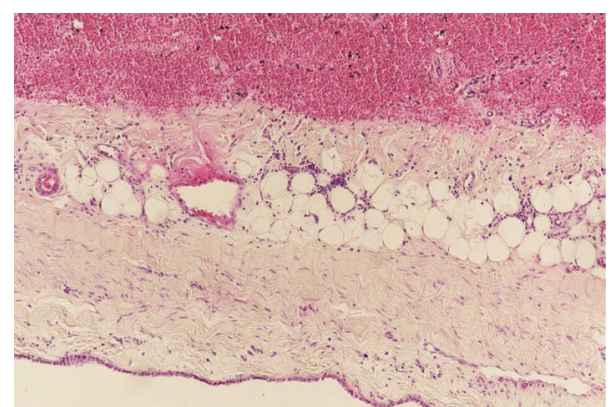

Figure 1: Histopathology $(\times 100)$. Fibrosis and hemorrhage in pleura.

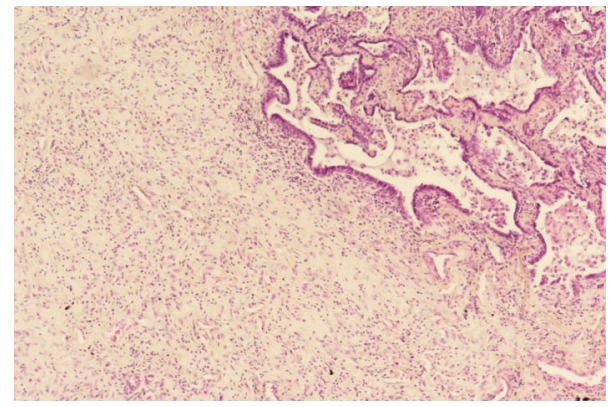

FIGURE 2: Histopathology $(\times 100)$. Interstitial pneumonia.

examination of the blood showed white blood cells at 26.9 $\times 10^{9} / \mathrm{L}$ and procalcitonin at $64.59 \mathrm{ng} / \mathrm{mL}$. He was clinically diagnosed as sepsis. He lost consciousness and progression of respiratory distress, resulting in cardiopulmonary arrest and death. We performed autopsy on that day. The pleura was replaced due to bleeding and fibrous thickening (Figure 1). In addition, alveolar wall was severely thick and inflamed, suggesting compatibility with the finding of interstitial pneumonia (Figure 2). He had peritonitis with marked pus in the colon (Figure 3) as well as full-thickness necrotic tissues of the colon from the mucosal (Figure 4(a)) to serous membrane (Figure 4(b)). Severe infiltration of ameba was detected in microvessel of colon (Figure 5(a)). We performed PAS staining for positive detection of ameba in colon (Figure 5(b)). Severe neutrophil infiltration was observed in liver, spleen, colon, stomach, pancreas, heart, and lungs, suggesting compatibility with the findings of sepsis (data not shown).

\section{Discussion}

We pathologically found severe fibrosis of alveolar wall and pleura. These findings are compatible with rheumatoid lung disease, suggesting that he had been suffering from the disease for a prolonged period. There was also the possibility of amebic infection.

Amebiasis is caused by the protozoan Entamoeba histolytica, which dominantly affects the colon and liver. The main route of transmission depends on ingestion of amebae from food or water contaminated with feces $[7,8]$. A majority of infected patients remain asymptomatic. However, acute

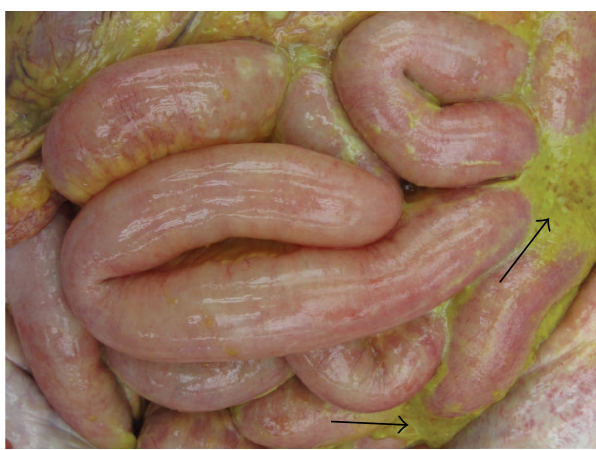

Figure 3: Pus in the colon.

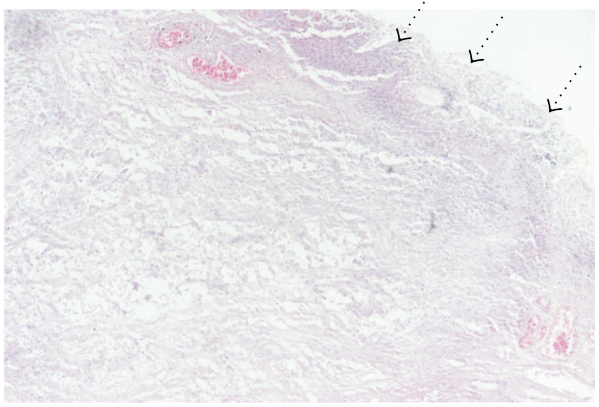

(a)

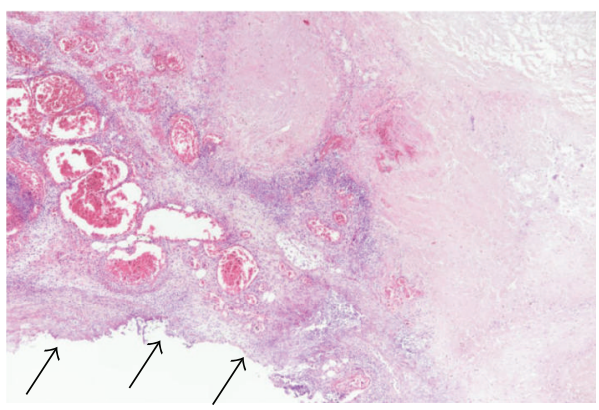

(b)

Figure 4: Histopathology $(\times 100)$. Necrosis from mucous membrane (a) to serous membrane (b). Dotted arrow shows mucous membrane. Black arrow shows serous membrane.

fulminant amebic colitis can be fatal [9]. Although amebiasis is not epidemic in Japan, the prevalence is increasing due to sexually transmitted diseases $[10,11]$. In particular, the increasing prevalence is largely attributed to more people travelling to affected geographical locations, as well as a rise in the prevalence of HIV and male homosexuality [10, 11]. In this case, the patient was HIV-negative, and we could not determine if he had travelled to an affected area.

Therefore, the etiology of the amebic infection remained unknown.

Generally, amebic colitis affects the mucosa and its surrounding $[5,6,12,13]$. However, few reports had shown that steroid treatment for inflammatory bowel disease induced amebic colitis treated by steroid colonic perforation with fullthickness necrosis [8]. We found amebic colitis with fullthickness necrosis and perforation as well as amebic infection 


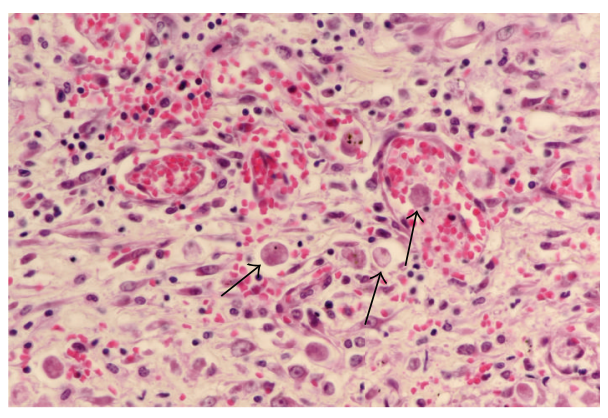

(a)

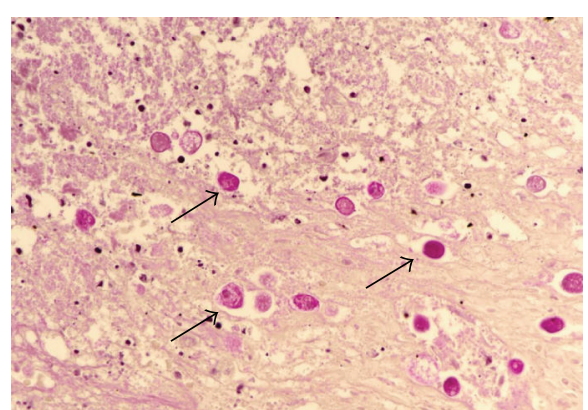

(b)

Figure 5: Histopathology $(\times 400)$. Infiltration of ameba in the colon. Arrow shows ameba. (a) Hematoxylin and eosin staining. (b) Periodic acid-Schiff staining.

in the liver and fat tissue around the pancreas. In addition, we observed vascular infiltration of ameba in the colon and liver, suggesting that the amebic infection has spread to other organs via the vascular system. RA and prolonged and high dosed steroid treatment may have induced the amebic infection, which could be the reasons for the patient's severe infection. The cause of death may be due to bacterial sepsis.

In conclusion, severe amebic infection may induce transmural necrosis and perforation of colon. RA and prolonged and high dosed steroid treatment may be important risk factors for fulminant amebic colitis.

\section{Competing Interests}

The authors declare no conflict of interests.

\section{Acknowledgments}

The authors thank Shenli Hew from the Department of Clinical Research Center for proofreading and editing the paper.

\section{References}

[1] A. Hashimoto and T. Matsui, "Risk of serious infection in patients with rheumatoid arthritis," Japanese Journal of Clinical Immunology, vol. 38, no. 2, pp. 109-115, 2015.

[2] P. Mayer, J. Larkin, and J. Hennessy, "Amebic encephalitis," Surgical Neurology International, vol. 2, article 50, 2011.

[3] C. I. Kobayashi, G. Yamamoto, A. Hayashi et al., "Fatal amebic colitis after high-dose dexamethasone therapy for newly diagnosed multiple myeloma," Annals of Hematology, vol. 90, no. 2, pp. 225-226, 2011.

[4] T. H. Mogensen, J. J. Christiansen, M. V. Eivindson, C. S. Larsen, and A. Tottrup, "Misdiagnosed amoebic colitis leading to severe dysentery and necrotizing colitis-report of a case and review of the literature," Scandinavian Journal of Infectious Diseases, vol. 46, no. 3, pp. 235-239, 2014.

[5] M. S. Niederman, L. A. Mandell, A. Anzueto et al., "Guidelines for the management of adults with community-acquired pneumonia. Diagnosis, assessment of severity, antimicrobial therapy, and prevention," American Journal of Respiratory and Critical Care Medicine, vol. 163, no. 7, pp. 1730-1754, 2001.
[6] D. A. White, "Drug-induced pulmonary infection," Clinics in Chest Medicine, vol. 25, no. 1, pp. 179-187, 2004.

[7] S. L. Stanley Jr., "Amoebiasis," The Lancet, vol. 361, no. 9362, pp. 1025-1034, 2003.

[8] S. S. Gupta, O. Singh, S. Shukla, and M. K. Raj, "Acute fulminant necrotizing amoebic colitis: a rare and fatal complication of amoebiasis: a case report," Cases Journal, vol. 2, no. 9, article $6557,2009$.

[9] T. Torigoe, Y. Nakayama, and K. Yamaguchi, "Development of perianal ulcer as a result of acute fulminant amoebic colitis," World Journal of Gastroenterology, vol. 18, no. 34, pp. 4794-4797, 2012.

[10] N. Nagata, T. Shimbo, J. Akiyama et al., "Risk factors for intestinal invasive amebiasis in Japan, 2003-2009," Emerging Infectious Diseases, vol. 18, no. 5, pp. 717-724, 2012.

[11] N. Horiki, K. Furukawa, T. Kitade et al., "Endoscopic findings and lesion distribution in amebic colitis," Journal of Infection and Chemotherapy, vol. 21, no. 6, pp. 444-448, 2015.

[12] K. A. Alavi, "Amebiasis," Clinics in Colon and Rectal Surgery, vol. 20, no. 1, pp. 33-37, 2007.

[13] R. Singh, A. Balekuduru, E. Simon, M. Alexander, and A. Pulimood, "The differentiation of amebic colitis from inflammatory bowel disease on endoscopic mucosal biopsies," Indian Journal of Pathology and Microbiology, vol. 58, no. 4, pp. 427432, 2015. 


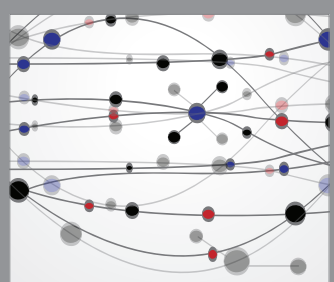

The Scientific World Journal
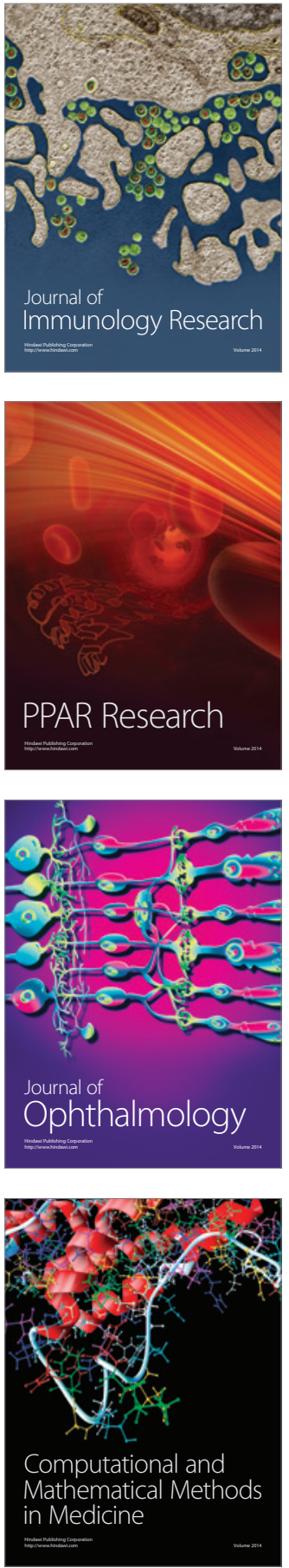

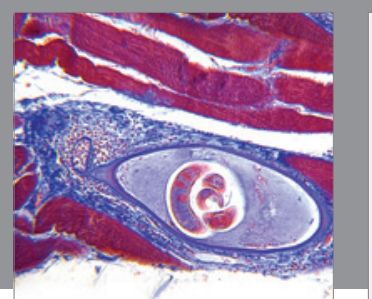

Gastroenterology Research and Practice

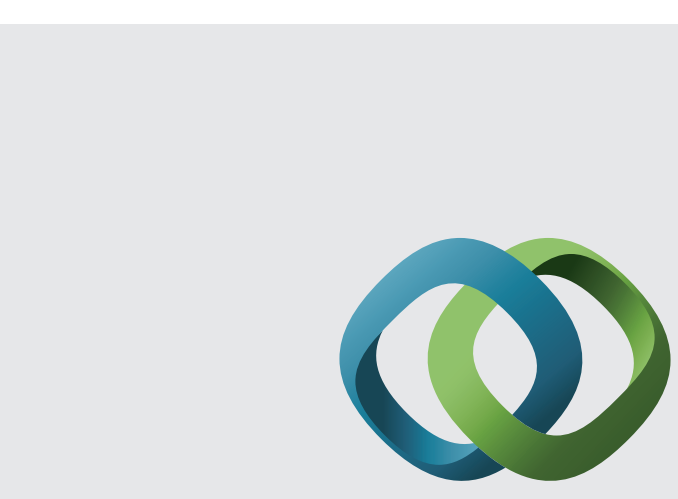

\section{Hindawi}

Submit your manuscripts at

http://www.hindawi.com
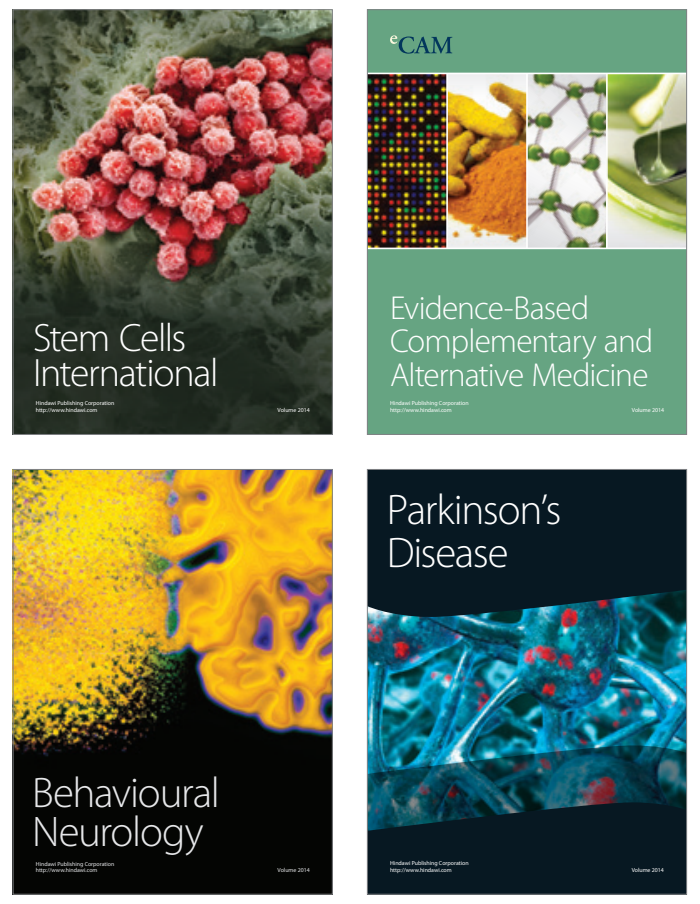
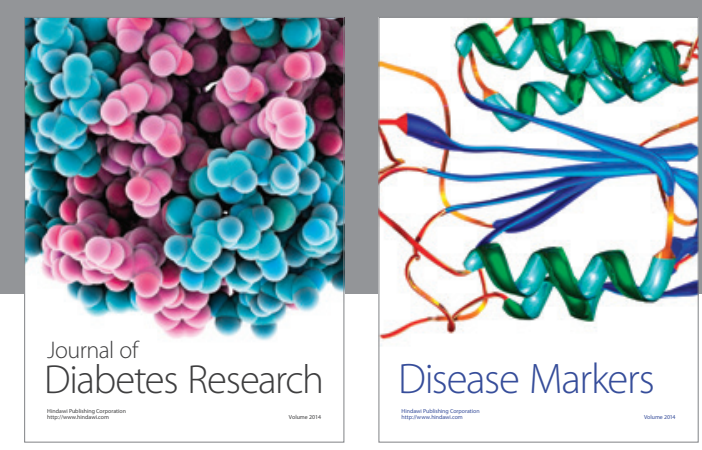

Disease Markers
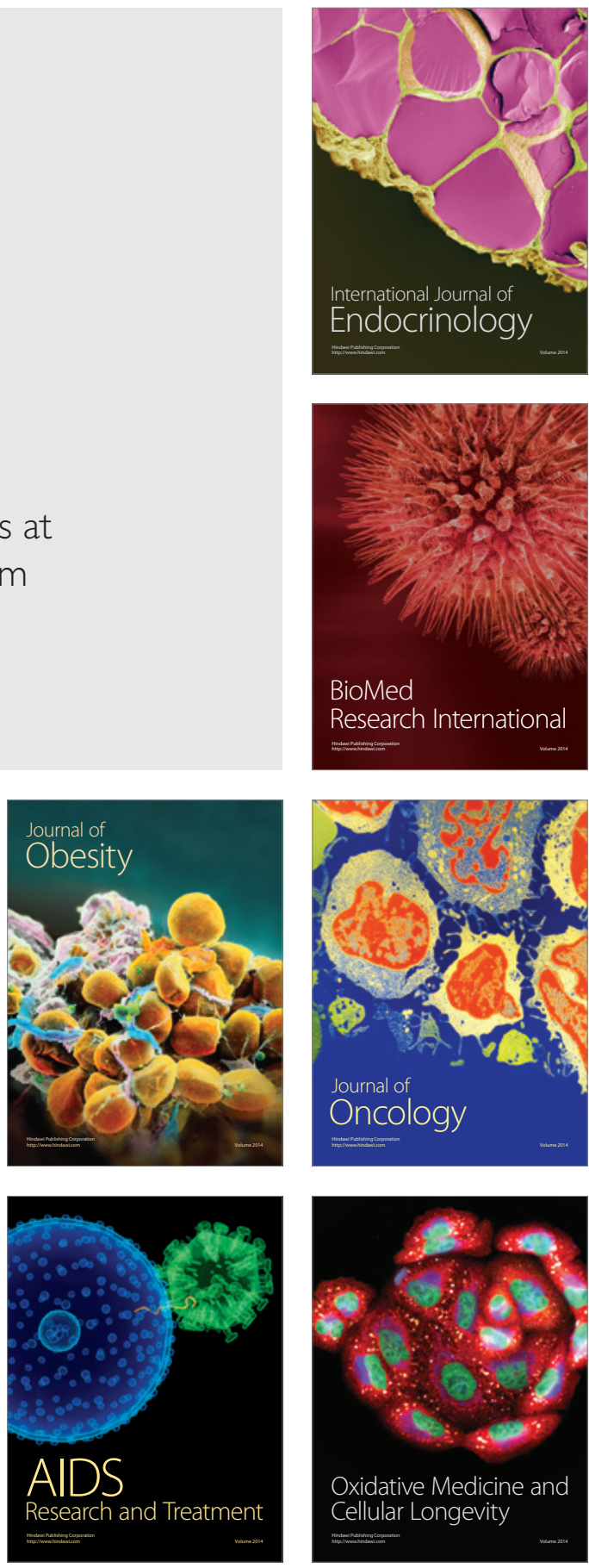